BMJ Health \& Care Informatics

\title{
Effectiveness of the eCARE programme: a short message service for asthma monitoring
}

\author{
Lathy Prabhakaran, Yap Chun Wei
}

To cite: Prabhakaran L, Chun Wei Y. Effectiveness of the eCARE programme: a short message service for asthma monitoring. BMJ Health Care Inform 2019;26:e100007. doi:10.1136/ bmjhci-2019-100007

- Additional material is published online only. To view please visit the journal online (http://dx.doi.org/10. 1136bmjhci-2019-100007).

Accepted 07 May 2019
Check for updates

(C) Author(s) (or their employer(s)) 2019. Re-use permitted under CC BY-NC. No commercial re-use. See rights and permissions. Published by BMJ.

Nursing Service, Tan Tock Seng Hospital, Singapore, Singapore

Correspondence to Lathy Prabhakaran;

lathy_prabhakaran@ttsh.com.sg

\section{ABSTRACT}

Objective To evaluate the effectiveness of the upgraded eCARE monitoring system on asthma control in discharged emergency department (ED) patients.

Methods A multicentre randomised controlled study (randomised controlled trial) was done for patients with a primary diagnosis of asthma seen at the EDs in Singapore between 1 March 2013 and 28 February 2015. Those who met the inclusion criteria were randomised into a control group (routine care, $n=212$ ) and intervention group (eCARE, $n=212$ ). Patients in the intervention group received short message service (SMS) messages according to a structured workflow, while patients in the control group did not receive SMS support.

Results For patients with poorly controlled asthma at recruitment, the results at 5 weeks showed no statistical difference in the proportion of patients who attained well-controlled asthma between the eCARE and routine care groups. At 3 months, the routine care group had a higher proportion of patients with well-controlled asthma but this was not statistically significant after adjustment for baseline differences using logistic regression. Approximately $95 \%$ of patients under the eCARE programme were satisfied with the SMS service. Discussion Patients in the eCARE programme did not have better asthma control than those receiving routine care. Conversely, patients in the eCARE programme appeared to have poorer asthma control, though a larger sample size will be required to confirm this finding.

\section{INTRODUCTION}

Since its launch and development in the 1990s, the short message service (SMS) has become widely attractive to researchers ${ }^{1}$ and medical practitioners for chronic disease management programmes. ${ }^{2-4}$ This is particularly so in programmes where data collection and follow-up monitoring is frequently required, usually over a significant period of time. Technological advances have enabled chronic self-management programmes and clinical studies to move from traditional monitoring systems, typically via the telephone and/or paper and pencil, to modern monitoring systems that capitalise on the conveniences of the internet and smartphones. ${ }^{1}$

\section{Summary box}

What is already known?

- A system to monitor asthma symptoms and frequency of use of relievers.

- A reminder to take their preventive inhaler.

- eCARE improves asthma control for inpatient discharge after an exacerbation.

What does this paper add?

- eCARE did not improve asthma control for patients discharged after an exacerbation from emergency department.

- Healthcare utilisation was similar in eCARE and those receiving routine care.

- Almost all patients under eCARE were satisfied with the short message service.

How might it impact on clinical practice in the foreseeable future?

- eCARE is well accepted by patients but was not effective in improving asthma control.

In Singapore, the eCARE home monitoring service via SMS was developed in 2007 to monitor patients' asthma symptoms and remind patients to take their medication. It was our first pilot study to examine the feasibility and impact of the eCARE programme on patients with asthma enrolled from inpatient settings. ${ }^{5}$ The study suggested that SMS reminders were effective to improve asthma control scores but did not reduce the number of emergency department (ED) visits or hospital admission. However, the feasibility of using the SMS was limited by language and age, with $25 \%$ of patients unable to speak English. Yet the compliance to responding to SMS messages was high $(82 \%)$ and the majority of patients $(95 \%)$ were satisfied with the programme. The limitation in the eCARE system from the first study was taken into consideration. Consequently, in 2012, adjustments were made to the eCARE programme to support an additional two languages, Mandarin and Malay, and the duration of SMS monitoring was reduced from 12 to 5 weeks. 
The scheduled SMS reminder was moved from 17:00 to 13:00 to allow asthma nurses to respond to eCARE alerts during working hours and monitor patients for shorter duration. Technical errors in the previous system were also rectified.

In this study, we designed a randomised controlled trial using the upgraded eCARE monitoring system for asthma cases seen at the EDs of two institutions in Singapore (Tan Tock Seng Hospital and National University Hospital). The primary objectives of this study were: (1) to evaluate the effectiveness of the eCARE programme on asthma control; (2) to determine the satisfaction level of patients on eCARE programme; and (3) to evaluate the healthcare utilisation among patients in eCARE programme with control group.

The rationale for this study was that if the eCARE system was found effective in improving asthma control, then it could be easily implemented as a new improved ED-based asthma intervention.

\section{METHODOLOGY \\ eCARE home monitoring information technology system}

This was a randomised controlled study and was approved by the National Healthcare Group Domain Specific Review Board. The workflow of the eCARE monitoring is shown in online supplementary figure S1. The eCARE system was used to monitor patients' asthma symptoms and remind them to take their medication. For patients who repeatedly reported poor control of the symptoms, the system would alert asthma nurses directly via email and SMS. On receiving the alert, nurses would call up the patients and advise them accordingly during office hours, in matters of adhering to medication or seeking medical help. Patients were advised to seek medical assistance from general practitioner (GP) or ED in the event of rapid deterioration of their condition. Where weekend exacerbations were reported, a phone call was carried out on the next working day. Each patient was equipped with a personal first aid asthma plan to self-manage their condition and was provided with the contact number of their asthma nurse who enrolled them in the study.

\section{Study subjects}

Participants were recruited from the EDs of two main teaching institutions in Singapore: Tan Tock Seng Hospital and National University Hospital. All patients with a primary diagnosis of asthma between 1 March 2013 and 28 February 2015 were screened by asthma nurses for enrolment into the study. To be included, patients had to (1) be aged 21 years and above; (2) own a mobile phone; (3) know how to use an SMS system; (4) report poor or partly controlled asthma (asthma control test (ACT) score of 5-19); and (5) be willing to participate in the study and give written consent. Patients who were excluded were those who (1) had significant comorbidity (eg, bronchiectasis, heart failure, diabetes mellitus with complication, stroke, renal impairment, chronic obstructive pulmonary disease); (2) did not know how to use an SMS system, or (3) had mild intermittent asthma.

\section{Sample size calculation}

Sample size was calculated assuming a $20 \%$ and $10 \%$ difference in ACT scores between control and intervention groups at 3 months for those with poorly controlled asthma and partially controlled asthma at baseline, respectively. Alpha was fixed at 0.05 and power at 0.80 . These led to a calculated sample size of 106 patients per arm for those with poorly controlled asthma and 328 patients per arm for those with partially controlled asthma.

\section{Asthma education}

All patients recruited in the study went through an individualised asthma education with a trained asthma nurse. This session was tailored to the patients' educational needs. The assessment was carried out through the use of a pro-forma. The nurse obtained the patients' asthma history, frequency of healthcare utilisations, past nearfatal asthma episodes, triggers and adherence to medication. The asthma control score of the patient, in addition to other measures such as age, gender and duration of asthma symptoms, was measured on enrolment to the study. The asthma nurse also assessed patients' inhaler techniques and identified possible barriers to their treatment. This face-to-face asthma education programme involved discussion on the basic mechanisms of asthma, including common triggers and an explanation of the changes which occur to the airways resulting in the symptoms experienced by the patient. Lifestyle choices and occupation that can trigger asthma were discussed, where appropriate, with the individual. The need for 'preventer' and 'reliever' medication was also emphasised during this session. Patients were provided postemergency discharge plans and asthma first aid advice to assist them in managing subsequent episodes of asthma attack. These sessions last on average $30 \mathrm{~min}$.

\section{Randomisation}

Patients who met the inclusion criteria and consented to participation were randomised to the intervention or control group. Randomisation was done using cards printed with either 'Intervention' or 'Control' on them. The cards were ordered according to a randomisation table unknown to the asthma nurses and placed individually in opaque envelopes. During recruitment, the asthma nurses will take the top envelope from the stack and use the card inside it to assign the patient to the intervention or control group. The card and envelope was then discarded.

Patients in the control group received routine care, that is, patients were given an appointment to see their primary care provider. At follow-up outpatient care, they were seen by both respiratory physician and asthma nurse where they received assessment, treatment review, education and reinforcement of asthma action plan. Patients in the intervention group were enrolled into the eCARE 
programme where they received SMS monitoring (daily for 1-2 weeks, then weekly for 3 weeks) to assist with the management of their asthma control. An asthma nurse would be in charge of monitoring the patient's response via the work phone. Reminder messages were sent to the assigned asthma nurse if patients did not respond to the SMS. If patients reported breathlessness or the need to use their reliever medications on 4 or more days in a week (not necessarily consecutively), the asthma nurse would be alerted via email and SMS. Subsequently, the asthma nurse would call the patient and provide necessary counselling. If the patient's asthma control did not show subsequent improvement, then the asthma nurse could provide a fast-track appointment to either specialist outpatient clinic or GP or polyclinic (online supplementary figure $\mathrm{S} 1$ ).

\section{Outcome assessment}

Outcome of asthma control and healthcare utilisation were assessed over the phone at 5 weeks and 3 months for all patients. The ACT is a 5-item questionnaire that assesses interference with activity, shortness of breath, nocturnal symptoms, rescue medication use and selfrating of asthma control. ${ }^{6}$ In Singapore, the ACT is available in English, Mandarin and Malay languages. The ACT score ranges from 5 to 25 where scores of 5-14 represent poorly controlled asthma and 15-19 represent partly controlled asthma. A score of 20 and above represents well-controlled asthma. During the first consultation, the patients were asked to complete the ACT with an asthma nurse's assistance. At the 5 weeks and 3 months' points, patients' ACT was assessed via phone interviews.

For patients in the intervention group, a survey on satisfaction with programme was also done at 5 weeks. Patients in the intervention group were asked, 'Are you satisfied with the SMS service?' The patients' responses to this question were measured using a 5-point Likert scale ( $1=$ 'strongly disagree' to $5=$ "strongly agree') .

Termination of SMS monitoring could take place under any of the following four scenarios: (1) the patient completed the cycle of monitoring (daily and weekly) without triggering any alerts; (2) the patient refused to reply to SMS; (3) the patient requested to end monitoring; or (4) the patient was hospitalised.

The number of asthma-related ED visits and hospital admissions at the 5 weeks and 3 months was obtained from administrative databases for all the patients.

\section{Statistical analysis}

An 'intention-to-treat' approach was used for the analyses. Bivariate analyses were conducted in order to compare the baseline characteristics of the intervention and control groups. Logistic regression analyses were used to compare the difference in proportion of patients achieving well-controlled asthma at the 5 weeks and 3 months between the intervention and control groups, adjusting for baseline differences between the groups.

\begin{tabular}{|c|c|c|c|}
\hline & $\begin{array}{l}\text { eCARE } \\
(n=212)\end{array}$ & $\begin{array}{l}\text { Routine } \\
(n=212)\end{array}$ & $P$ value \\
\hline ACT score, mean (SD) & $13.9(3.4)$ & $14.4(3.6)$ & 0.139 \\
\hline Asthma control, $\mathrm{n}(\%)$ & & & 0.024 \\
\hline Poor (5-14) & $106(50.0)$ & $82(38.7)$ & \\
\hline Partial (15-19) & $106(50.0)$ & $130(61.3)$ & \\
\hline $\begin{array}{l}\text { Duration of asthma (years), } \\
\text { mean (SD) }\end{array}$ & $23.6(16.4)$ & $28.2(18.4)$ & 0.006 \\
\hline Age, mean (SD) & $37.1(12.6)$ & $40.5(15.9)$ & 0.017 \\
\hline Gender, n (\%) & & & 0.377 \\
\hline Male & $85(40.1)$ & $95(44.8)$ & \\
\hline Female & $127(59.9)$ & $117(55.2)$ & \\
\hline Race, n (\%) & & & 0.119 \\
\hline Chinese & $42(19.8)$ & $62(29.2)$ & \\
\hline Malay & $113(53.3)$ & $99(46.7)$ & \\
\hline Indian & 47 (22.2) & $45(21.2)$ & \\
\hline Others & $10(4.7)$ & $6(2.8)$ & \\
\hline Smoking, $\mathrm{n}(\%)$ & $54(25.5)$ & $64(30.2)$ & 0.329 \\
\hline Comorbidities, n (\%) & & & 0.373 \\
\hline 0 & $181(85.4)$ & $170(80.2)$ & \\
\hline 1 & $21(9.9)$ & $26(12.3)$ & \\
\hline 2 & $6(2.8)$ & $13(6.1)$ & \\
\hline 3 & $2(0.9)$ & $1(0.5)$ & \\
\hline 4 & $1(0.5)$ & $2(0.9)$ & \\
\hline 5 & $1(0.5)$ & $0(0.0)$ & \\
\hline Receiving treatment, $\mathrm{n}(\%)$ & & & 0.668 \\
\hline GP & $86(40.6)$ & 95 (44.8) & \\
\hline SOC & $49(23.1)$ & 40 (18.9) & \\
\hline Polyclinic & $46(21.7)$ & $49(23.1)$ & \\
\hline Others & $31(14.6)$ & 28 (13.2) & \\
\hline
\end{tabular}

ACT, asthma control test; GP, general practitioner; SOC, specialist outpatient clinic.

The proportion of patients satisfied with the intervention was reported.

\section{RESULTS}

During the 2-year period (1 March 2013 and 28 February 2015), a total of 424 patients were randomised to the eCARE programme $(n=212)$ and routine care $(n=212)$. Since the 'intention-to-treat' approach was used to analyse the clinical outcomes at the 5 weeks and 3 months, online supplementary figure $\mathrm{S} 2$ describes the study population at each stage. The baseline characteristics are given in table 1. It can be seen that patients under the eCARE programme were generally younger (mean age 37.1 ) and had shorter asthma duration (23.6 years).

Table 2 shows the comparison of outcomes between patients under the eCARE programme and routine care. At the 5-week follow-up, a total of 46 patients from the eCARE programme and 42 patients from routine care dropped out from the study. There is no statistical 
Table 2 Comparison of outcomes between patients under eCARE programme and routine care at 5 weeks

\begin{tabular}{|c|c|c|c|}
\hline & $\begin{array}{l}\text { eCARE } \\
(n=166)\end{array}$ & $\begin{array}{l}\text { Routine } \\
(n=170)\end{array}$ & $P$ value \\
\hline $\begin{array}{l}\text { Poor/partial to well controlled, } n \\
\text { (\%) }\end{array}$ & $115(69.3)$ & $138(81.2)$ & 0.016 \\
\hline Poor to well controlled, $\mathrm{n}(\%)$ & 59 (70.2) & $50(75.8)$ & 0.468 \\
\hline Partial to well controlled, $\mathrm{n}(\%)$ & $56(68.3)$ & $88(84.6)$ & 0.013 \\
\hline $\begin{array}{l}\text { ACT change (baseline to } 5 \text { weeks), } \\
\text { mean (SD) }\end{array}$ & $6.6(5.7)$ & $7.1(5.1)$ & 0.420 \\
\hline Asthma-related ED visits, $\mathrm{n}(\%)$ & 17 (10.2) & $16(9.4)$ & 0.856 \\
\hline Asthma-related admissions, $\mathrm{n}(\%)$ & $8(4.8)$ & $7(4.1)$ & 0.797 \\
\hline \multicolumn{4}{|l|}{ Satisfied with SMS service, $\mathrm{n}(\%)$} \\
\hline Strongly disagree & $0(0.0)$ & & \\
\hline Disagree & $4(2.4)$ & & \\
\hline Neutral & $4(2.4)$ & & \\
\hline Agree & $137(82.5)$ & & \\
\hline Strongly agree & $21(12.7)$ & & \\
\hline
\end{tabular}

ACT, asthma control test; ED, emergency department; SMS, short message service.

difference between the proportion of patients who had asthma-related ED visits or hospital admissions between the eCARE and routine care groups $(\mathrm{p}=0.856$ and $\mathrm{p}=0.797$, respectively). Approximately $95 \%$ of patients under the eCARE programme were satisfied with the SMS service.

Logistic regression was used to adjust for age, gender, race, asthma duration, baseline ACT score, smoking, number of comorbidities and initial place of asthma treatment. The results given in table 3 showed that patients who had partially controlled asthma at baseline were statistically more likely to achieve well-controlled asthma for the routine care group compared with the eCARE group $(p=0.043)$. For patients with poor-controlled asthma at baseline, there is no statistical difference in the proportion of patients who attained well-controlled asthma between the eCARE and routine care groups $(\mathrm{p}=0.744)$.

At the 3-month follow-up, a total of 159 patients from the eCARE programme and 162 patients from routine care remained in the study. Table 4 shows the comparison of outcomes between patients under the eCARE programme and routine care at 3 months. The routine care group had a higher proportion of patients with well-controlled asthma at the 3 months' point. There is no difference in the number of asthma-related ED visits $(\mathrm{p}=0.733)$ and hospital admissions $(\mathrm{p}=0.364)$ in both intervention and control groups.

Logistic regression shows that there is no statistical significance between the proportion of patients who

Table 3 Multivariate logistic regression for well-controlled asthma at 5 weeks

\begin{tabular}{|c|c|c|c|c|}
\hline & \multicolumn{2}{|c|}{ Poorly controlled asthma at baseline } & \multicolumn{2}{|c|}{ Partially controlled asthma at baseline } \\
\hline & OR $(95 \% \mathrm{Cl})$ & $P$ value & OR $(95 \% \mathrm{Cl})$ & $P$ value \\
\hline \multicolumn{5}{|l|}{ Patient group } \\
\hline eCARE & $0.90(0.48$ to 1.70$)$ & 0.744 & 0.56 (0.32 to 0.98$)$ & 0.043 \\
\hline Age & 1.03 (1.00 to 1.06$)$ & 0.070 & $1.03(1.00$ to 1.05$)$ & 0.019 \\
\hline Male & Reference & & Reference & \\
\hline Female & $0.59(0.30$ to 1.18$)$ & 0.136 & $0.69(0.38$ to 1.25$)$ & 0.222 \\
\hline \multicolumn{5}{|l|}{ Race } \\
\hline Chinese & Reference & & Reference & \\
\hline Duration of asthma (years) & 1.01 (0.98 to 1.03$)$ & 0.602 & 0.99 (0.97 to 1.01$)$ & 0.422 \\
\hline Baseline ACT score & $0.92(0.81$ to 1.04$)$ & 0.187 & $1.16(0.95$ to 1.41$)$ & 0.140 \\
\hline Smoking & $0.76(0.36$ to 1.61$)$ & 0.471 & $0.60(0.32$ to 1.14$)$ & 0.121 \\
\hline Comorbidities, n & 0.83 (0.52 to 1.32$)$ & 0.424 & 0.66 (0.43 to 1.03$)$ & 0.065 \\
\hline \multicolumn{5}{|c|}{ Initial place of asthma treatment } \\
\hline GP & Reference & & Reference & \\
\hline SOC & $0.47(0.20$ to 1.11$)$ & 0.086 & $0.72(0.34$ to 1.55$)$ & 0.405 \\
\hline Polyclinic & 0.91 (0.41 to 2.04) & 0.819 & 0.83 (0.39 to 1.78$)$ & 0.631 \\
\hline Others & $0.43(0.15$ to 1.19$)$ & 0.104 & 0.69 (0.30 to 1.60$)$ & 0.391 \\
\hline
\end{tabular}

$\mathrm{ACT}$, asthma control test; GP, general practitioner; SOC, specialist outpatient clinic. 
Table 4 Characteristics of patients at 3 months

\begin{tabular}{llll}
\hline & $\begin{array}{l}\text { eCARE } \\
(\mathbf{n = 1 5 9 )}\end{array}$ & $\begin{array}{l}\text { Routine } \\
(\mathbf{n}=162)\end{array}$ & P value \\
\hline $\begin{array}{l}\text { Poor/partial to well controlled, } \\
\mathrm{n}(\%)\end{array}$ & $112(70.4)$ & $137(84.6)$ & 0.003 \\
\hline $\begin{array}{l}\text { Poor to well controlled, } \mathrm{n}(\%) \\
58(71.6)\end{array}$ & $54(83.1)$ & 0.118 \\
\hline $\begin{array}{l}\text { Partial to well controlled, } \mathrm{n}(\%) \\
\text { ACT change (baseline to 3 }\end{array}$ & $7.3(69.2)$ & $83(85.6)$ & 0.010 \\
$\begin{array}{l}\text { months), mean (SD) } \\
\text { Asthma-related ED visits, } \mathrm{n}(\%)\end{array}$ & $18(11.3)$ & $21(13.0)$ & 0.383 \\
$\begin{array}{l}\text { Asthma-related admissions, } \\
\mathrm{n}(\%)\end{array}$ & $12(7.5)$ & $8(4.9)$ & 0.364 \\
\hline
\end{tabular}

$\mathrm{ACT}$, asthma control test; ED, emergency department.

attained well-controlled asthma between the eCARE and routine care groups, as shown in table 5 .

\section{DISCUSSION}

After excluding those who had dropped out, it was found that $70.2 \%$ of eCARE patients and $75.8 \%$ of routine care patients achieved well-controlled asthma at 5 weeks. Logistic regression analysis showed that there is no statistical difference in the proportion of patients with poor-controlled asthma at baseline who attained well-controlled asthma at the 5-week follow-up between the intervention and control groups $(\mathrm{p}=0.744)$. A similar trend was found at the 3-month follow-up, with $71.6 \%$ of eCARE patients and $83.1 \%$ of routine care patients progressed from poor baseline control to well-controlled asthma. After adjustment using logistic regression, the results showed no statistical difference in the proportion of patients who attained well-controlled asthma in the eCARE group versus the routine care group. In other words, the vast majority of patients, with or without the combination of intervention methods, demonstrated well-controlled asthma at the 5 weeks and 3 months' points.

It is well known that provision of information and empowerment of patients in any form of self-management programme typically leads to achievable asthma control. ${ }^{7}$ In this study, our programme consists of asthma counselling where all patients recruited in this study were thoroughly counselled by a trained asthma nurse on disease knowledge, correct inhaler technique and the necessity of inhaled corticosteroid treatment. For the eCARE group, they also received daily and weekly SMS reminders. Our results suggest that eCARE, which was thought to create a higher patient awareness of asthma symptoms, while also reminding patients to adhere to

Table 5 Multivariate logistic regression for well-controlled asthma at 3 months

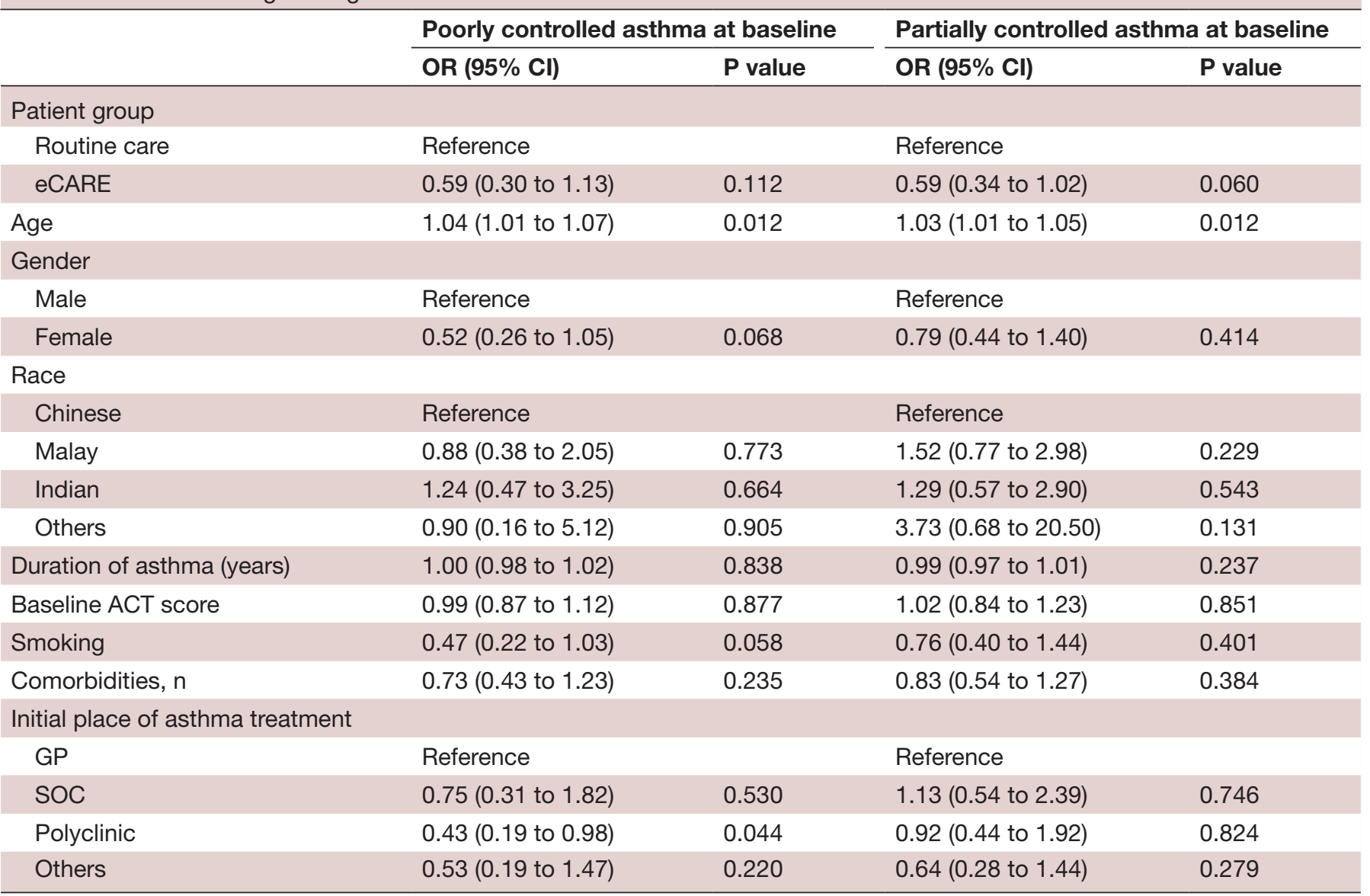

$\mathrm{ACT}$, asthma control test; GP, general practitioner; SOC, specialist outpatient clinic. 
their medication, did not result in improvements in asthma control.

These findings were dissimilar from those of our initial study where greater improvement in ACT (to greater than 20 points) was seen in the intervention group compared with the control group, though the earlier result was not statistically significant. ${ }^{5}$ There could be several reasons for the ineffectiveness of eCARE. The first was that the eCARE monitoring in this study was shorter compared with the initial study, where the intervention group had 3 months of SMS monitoring. ${ }^{5}$ The frequency and length of monitoring was reduced to 5 weeks due to the feedback received from the first study, where some patients found the daily monitoring irritating and preferred weekly monitoring. Similar findings were reported by Strandbygaard $e t$ al. $^{8}$

Another possible reason is the clinical profile of patients in the eCARE group compared with the routine group displayed poor asthma control and were generally younger and had shorter durations of asthma. These patients might have had poor perception and insight to their disease, and should therefore have been subjected to more intensive education, monitoring and medical therapy for better outcomes. ${ }^{9}$ Our findings reveal that there is a need to address the profiles of patients with poor asthma control at EDs.

Decline in patient compliance rate as time passed could also be a reason. Charles $e t a l^{10}$ demonstrated a significant improvement in adherence to treatment with an audiovisual reminder device, but at the end of the 6-month study period no difference in clinical outcome between the groups was observed. In a yearlong study by Macedo et $a l,{ }^{1}$ who collected monthly data on lower back pain, patient response rate was lower than that of the study by Kongsted $e t a l,{ }^{11}$ who collected weekly pain measures for the lower back over a 4-month period. The differences between these studies were the frequency and duration of the SMS. Arguably, it was possible that more frequent contact would increase response rates and better clinical outcomes but it is difficult to stipulate the period of monitoring for good clinical outcomes. Strandbygaard et al reported that the improvements in clinical outcome were commonly seen in the beginning of a clinical trial. For initial improvements to revert, it could take more than 6 months.

The most likely reason is the eCARE is effective only for patients who forget to take their medications since it is essentially a reminder system. Patients who are compliant with their medications or those who are non-compliant on purpose are unlikely to benefit from eCARE.

At 5 weeks, a total of 46 patients from the eCARE programme had dropped out, and the number of participants further decreased over the remaining period of the study. This result was different from that of Macedo $e t$ $a l,{ }^{1}$ primarily due to the combination of systems in their study. Hence, SMS alone cannot be used as an alternative to traditional methods of outcome assessment. Macedo $e t$ $a l^{1}$ suggested the use of a hybrid system, such as the use of phone interviews for those who did not respond to the SMS, in order to achieve positive outcomes. This finding is an important factor when considering the use of SMS in longitudinal studies because compliance with the study protocol may become more difficult as time passes, as stated by Macedo et al. ${ }^{1}$

Approximately $95 \%$ of patients who remained under the eCARE programme were satisfied with the SMS service. This result was similar to our first study. Further studies should focus on methods to enhance monitoring according to patients' requirements whereby a patient can adjust the monitoring duration according to their needs on their own. This can potentially increase effectiveness and lead to other positive clinical outcomes.

The proportion of patients with asthma-related ED visits or hospital admissions at 3 months were less than $13 \%$ for ED visits and less than $8 \%$ for hospital admissions, and were not statistically different between the intervention and control groups. This suggests that eCARE programme did not affect healthcare utilisation among patients. This is expected since eCARE did not affect asthma control.

\section{Limitations}

A major limitation is the difficulty in the recruitment of patients into the study. This study had a limited sample size; only 424 patients from two main institutions responded to our invitation to join over the period of 2 years of recruitment. We have observed that patients were reluctant to participate due to the research nature of this study. Caution should therefore be exercised when generalising the results.

\section{CONCLUSION}

In this study, patients in the eCARE programme did not have better asthma control than those receiving routine care. Contrary to expectations, these patients appeared to have poor asthma control, though a larger sample size will be required to confirm this finding. The majority of patients under the eCARE programme were satisfied with the SMS service. Healthcare utilisation was similar among patients in eCARE programme and control group.

Acknowledgements We thank Ms Wong Wai Mun, Ms Shu Yi Lee and Ms Nora Bte SAID for their contribution and assistance with this study.

Collaborators Yap, Chun Wei Neo, Lay Ping Gan, Chi Ching, Tham, Lai Mei John, Abisheganaden Lim, Tow Keng.

Funding The telemonitoring system for the study was funded by Singapore National Asthma Program.

Competing interests None declared.

Patient consent for publication Obtained.

Ethics approval National Healthcare Group Domain Specific Review Board (DSRB 2013/00112).

Provenance and peer review Not commissioned; externally peer reviewed.

Data sharing statement No data are available.

Open access This is an open access article distributed in accordance with the Creative Commons Attribution Non Commercial (CC BY-NC 4.0) license, which permits others to distribute, remix, adapt, build upon this work non-commercially, 
and license their derivative works on different terms, provided the original work is properly cited, appropriate credit is given, any changes made indicated, and the use is non-commercial. See: http://creativecommons.org/licenses/by-nc/4.0/.

\section{REFERENCES}

1 Macedo LG, Maher CG, Latimer J, et al. Feasibility of using short message service to collect pain outcomes in a low back pain clinical trial. Spine 2012;37:1151-5.

2 Anhøj J, Møldrup C. Feasibility of collecting diary data from asthma patients through mobile phones and SMS (short message service): response rate analysis and focus group evaluation from a pilot study. $\checkmark$ Med Internet Res 2004;6:e42.

3 Ostojic V, Cvoriscec B, Ostojic SB, et al. Improving asthma contro through telemedicine: a study of short-message service. Telemed J E Health 2005;11:28-35.

4 Kwon H-S, Cho J-H, Kim H-S, et al. Development of web-based diabetic patient management system using short message Service (SMS). Diabetes Res Clin Pract 2004;66 Suppl 1:S133-S137.
5 Prabhakaran L, Chee WY, Chua KC, et al. The use of text messaging to improve asthma control: a pilot study using the mobile phone short messaging Service (SMS). J Telemed Telecare 2010;16:286-90.

6 Schatz M, Sorkness CA, Li JT, et al. Asthma control test: reliability, validity, and responsiveness in patients not previously followed by asthma specialists. J Allergy Clin Immunol 2006;117:549-56.

7 van der Meer V, van Stel HF, Detmar SB, et al. Internet-based selfmanagement offers an opportunity to achieve better asthma control in adolescents. Chest 2007;132:112-9.

8 Strandbygaard U, Thomsen SF, Backer V. A daily SMS reminder increases adherence to asthma treatment: a three-month follow-up study. Respir Med 2010;104:166-71.

9 Abisheganaden J, Sin Fai Lam KN, Lim TK, et al. A profile of acute asthma patients presenting to the emergency room. Singapore Med J 1996;37:252-4.

10 Charles T, Quinn D, Weatherall M, et al. An audiovisual reminder function improves adherence with inhaled corticosteroid therapy in asthma. J Allergy Clin Immunol 2007;119:811-6.

11 Kongsted A, Leboeuf-Yde C, Boston M. A proposal for a new followup tool: low back pain-patterns identifi ED by text messages 2009. 